\title{
A POPULATION DYNAMICAL MODEL OF OPEROPHTERA BRUMATA, L. EXTENDED BY CLIMATIC FACTORS
}

\author{
KÚtI, Zs. ${ }^{1}{ }^{*}-$ HIRKA, A. ${ }^{2}-$ HUfNAGEL, L. ${ }^{1}$ - LADÁNYI, M. ${ }^{1}$ * \\ ${ }^{I}$ Corvinus University of Budapest, Dept. of Mathematics and Informatics \\ H-1118 Budapest, Villányi út 29-43. \\ (phone: +36-1-482-6261; fax: +36-1-466-9273) \\ ${ }^{2}$ Hungarian Forest Research Institute, Dept. of Forest Protection \\ H-3232 Mátrafüred, Hegyalja út 18. \\ (phone: +36-37-320-129; fax: +36-37-520-047) \\ *Corresponding authors \\ e-mail:marta.ladanyi@uni-corvinus.hu,kutizsuzsi@gmail.com \\ (Received $13^{\text {th }}$ November 2011; accepted $2^{\text {nd }}$ December 2011)
}

\begin{abstract}
Setting out from the database of Operophtera brumata, L. in between 1973 and 2000 due to the Light Trap Network in Hungary, we introduce a simple theta-logistic population dynamical model based on endogenous and exogenous factors, only. We create an indicator set from which we can choose some elements with which we can improve the fitting results the most effectively. Than we extend the basic simple model with additive climatic factors. The parameter optimization is based on the minimized root mean square error. The best model is chosen according to the Akaike Information Criterion. Finally we run the calibrated extended model with daily outputs of the regional climate model RegCM3.1, regarding 1961-1990 as reference period and 2021-2050 with 2071-2100 as future predictions. The results of the three time intervals are fitted with Beta distributions and compared statistically. The expected changes are discussed.
\end{abstract}

Keywords: Operophtera brumata, L., population dynamical model, climatic indicators, climate change, $\operatorname{Reg} C M$

\section{Introduction}

Climate change is a global environmental problem, which has now become a central issue. According to the 2007 Fourth Assessment Report by the Intergovernmental Panel on Climate Change (IPCC), global surface temperature increased about $1{ }^{\circ} \mathrm{C}$ in the $20^{\text {th }}$ century and further $3-4{ }^{\circ} \mathrm{C}$ increment in mean temperature is predicted towards the end of the $21^{\text {st }}$ century. The rise of the number and intensity of the extreme meteorological events are the most serious consequence of global warming, which can result in the change of both the global and the regional climate.

The question about the way and rate the climatic factors and their changes affect the agricultural and forest pests was investigated by several researchers. The past and the expected effects of the climatic parameters to invertebrate populations have been measured in the previous years by a number of researchers (Drégelyi-Kiss et al., 2008, 2009; Sipkay et al., 2008, 2009; Diós et al., 2009; Bale et al., 2002). The impact on population dynamics of insect pests was studied earlier by Porter et al. (1991), Cammel and Knight (1992), Woiwod (1997) and recently by Estay et al. (2009). Parmesan (2007) focuses on phenological responses of insects while Merril et al. (2008), Musolin (2007) and Olfert and Weiss (2006) investigate complex effects.

In this paper the population dynamics of a multitudinous forest- and horticultural Lepidoptera pest species, the Operophtera brumata (Linnaeus, 1758) will be examined 
according to their most important endogenous and exogenous factors described by a first order density dependent reproductive function and meteorological parameters.

Operophtera brumata, L. is one of the earliest known forest- and fruit tree invasive pest species of Geometridae family occurring periodically in multitudinous colonies. During cool springs, if weather hinders leaf expansion, the winter moth caterpillar can cause high levels of injury to the leaves, thus examining its population dynamics is extremely important.

\section{Materials and methods}

Data of the National Plant Protection and Forestry Light Trap Network (1973-2000) with 252 traps were analysed. Traps are situated in nine regions (Felsőtárkány, GerlaGyula, Mátraháza, Répáshuta, Sopron, Szentpéterfölde, Tolna, Tompa, Várgesztes (Fig. 1)

The light trap network was developed in Hungary in the early 1960's by the Ministry of Agriculture and Food Plant Protection Service. More than 150 light traps are now more than 40 years old, providing data on swarming phenology for entomological research of great scientific value.

Light trap data of 28 years (1973-2000) with the same monitoring standard method were used for model evaluation. Operophtera brumata, L. was detected in each year and in each trap.

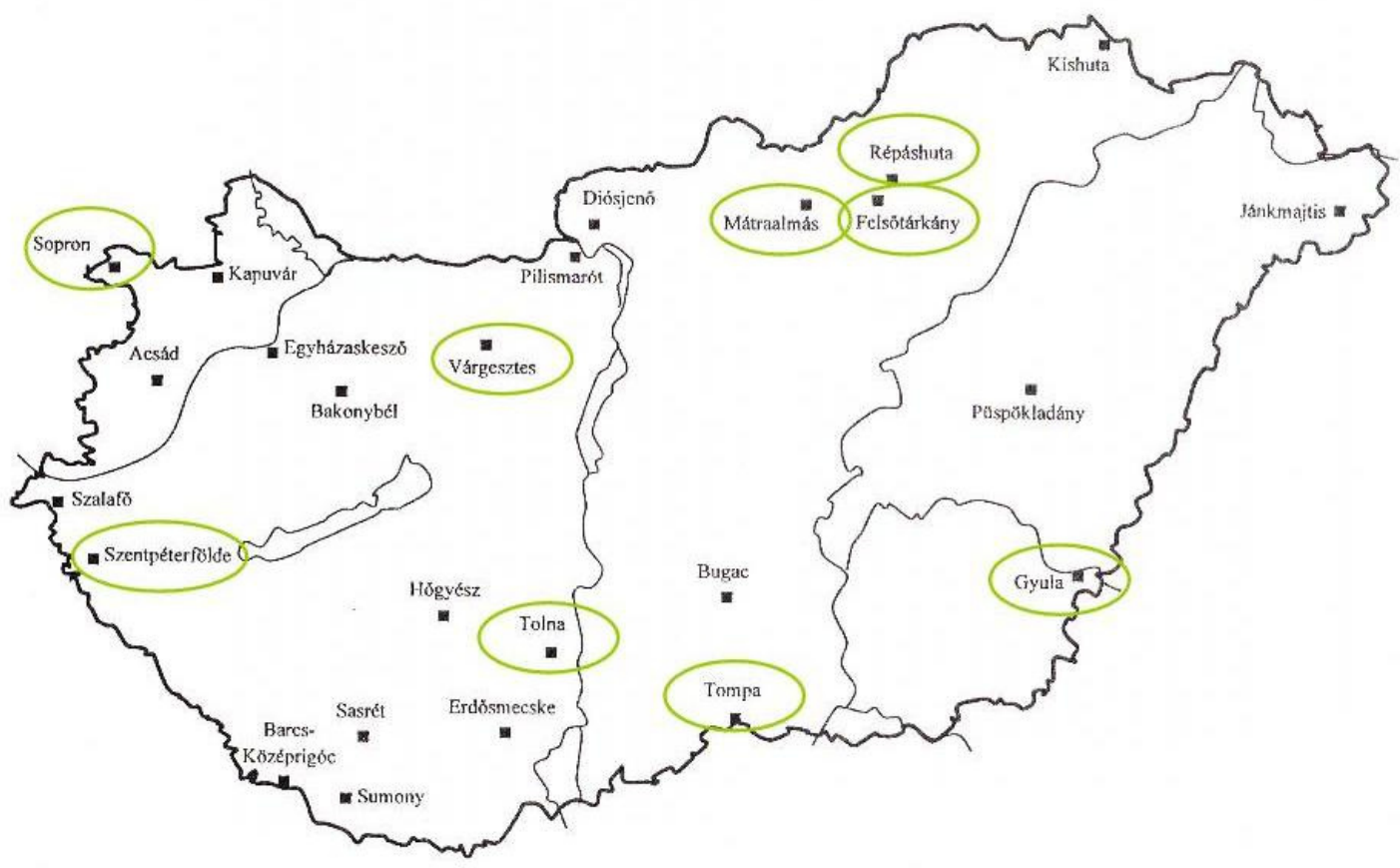

Figure 1. Light trap network in Hungary. The regions involved in the analysis are circled

The daily meteorological data (precipitation $[\mathrm{mm}]$, mean temperature $\left[{ }^{\circ} \mathrm{C}\right]$, maximal temperature $\left[{ }^{\circ} \mathrm{C}\right]$ and minimal temperature $\left[{ }^{\circ} \mathrm{C}\right]$ ) were taken from the Hungarian Meteorological Service. For climate change impact study we applied RegCM 3.1 which was downscaled at Eötvös Loránd University, Budapest, Department of Meteorology 
for A1B scenario (Giorgi et al., 1993; Bartholy et. al., 2009; Torma et. al., 2008). We considered three different time scales: 1961-1990 as reference period, 2021-2050 and 2071-2100 as prediction time intervals.

\section{Characterization of Operophtera brumata, $\mathrm{L}$.}

The Winter Moth (Operophtera brumata, L.) is a polyphagous moth of the family Geometridae. It is an abundant species of Europe and has been already introduced to North America and United Kingdom (England and Scotland) from Europe. The diversity of its food plants is very wide: oak, maple, chestnut, hazel, pear, basswood, ash, apple, cherry, blueberry, raspberry etc.

After mating in late fall or winter, the female lay 200-300 or in some years even 450500 eggs in clusters of 2-3 eggs, usually on tree trunks and branches. The adult moths then die and the eggs over-winter. Eggs hatch when the mean daily temperature is appropriate (over $12-13{ }^{\circ} \mathrm{C}$ ), usually in early-middle March. This means that egg-hatch can occur before bud break of some of its host plants. Young larvae (caterpillars) are tiny black headed dark colour inchworms and have just 2 pairs of prolegs.

They tunnel into buds where they feed, usually at night. These caterpillars move from bud to bud as they feed. They often crawl up tree trunks and produce a long silken strand of silk with the help of which they can "balloon". Delayed bud opening due to cool weather conditions can lead to bud death as the caterpillars have longer time to feed. Older larvae feed flowers and leaf clusters. A single species demands $40-50 \mathrm{~m}^{2}$ leaf area.

Larvae need, depending on weather, 25-40 days to maturity passing 5 phenophases $\mathrm{mm}$. At maturity, the caterpillars are $25-30 \mathrm{~mm}$ long. They feed voraciously until midMay, and then they start to migrate to the soil (up to 3-8 $\mathrm{mm}$ depth) under the tree for pupation. They will stay in the soil in a hard-covered pupal stage until, usually after some rainy days and not before the first fall frost, they emerge as adult moths on a late October day with no frost. Males are emerging usually some days earlier than females and occurrence is earlier in forests at 5-7 days than in orchards. The female is wingless and cannot fly, but the male is fully winged and flies strongly. The wingspan of a mature male is $28-33 \mathrm{~mm}$. The adults are active from sunset up to midnight, throughout the winter from October to January, even when there is lightly snowing. Males are attracted to light and females, activity of males increases significantly in case of low air pressure. Swarming lasts 6-8 weeks with eventually some pauses on heavy frosty days or great amount of snow. Optimal daily mean temperature for flying is $5-10{ }^{\circ} \mathrm{C}$, wet evenings are beneficial.

Moths (the adult stage) of the winter moth emerge from the soil usually in late November and can be active into January. The male moths are small, light brown to tan in colour and have four wings that are fringed with small elongate scales that give the hind margins a hairy or fringed appearance. The female is gray, wingless and, therefore, cannot fly. She emits a sex pheromone or scent that often attracts clouds of male moths. Females are usually found at the base of trees but can be found almost anywhere.

After copulation hours males live 2-3, females 8-9 days long. Long, warm and rainy falls are beneficial for the defoliation in high populations while it is impeded by cold and rainy springs. Late spring frosts can cause high mortality of caterpillars. Gradations develop very quickly, intensively, and persist for only a relatively short period of 3-5 years (Schwerdtfeger, 1969; Szontagh, 1980; Childs et al. 2009; Chinery, 1991) with a 
cycle of 10-11 years. Gradation peaks of Operophtera brumata, L. in Hungary were in years 1961, 1971, 1982, 1992.

For the sake of decreasing the modification effects of different abiotic factors and the different number of collections in different collection sites, we used the data merging, reducing, filtering and smoothing moving average methods (Moon and Kim, 2007; Heuvelink and Webster, 2001; Gimesi and Hufnagel, 2010). As a result, we got a dimensionless aggregated data set with a time series of yearly steps referring to the population size of Operophtera brumata, L species of a given year.

\section{The basic model}

We set out from a simple discrete population dynamical model (sometimes called the theta-logistic model):

$$
N_{t+1}=N_{t} * \exp \left(R_{\max } *\left(1-\frac{N_{t}}{K}\right)^{\theta}\right)
$$

which is a nonlinear version of the classic logistic model (Ricker, 1954; Verhulst 1838; Richards 1959; Nelder 1961; Gilpin and Ayala 1973; Berryman 1999). In the model we denote by $N_{t+1}$ the number of individuals in year $t+1$, which, through an exponential function, depends on the number of individuals in the previous year $N_{t}$, on the maximal growth rate $R_{\max }$, on the carrying capacity $K$ and on the power parameter $\theta$.

We introduce the notation $R_{t}$ as:

$$
R_{t}=\ln \left(\frac{N_{t+1}}{N_{t}}\right)=R_{\max } *\left(1-\frac{N_{t}}{K}\right)^{\theta}=R_{\max }-R_{\max }\left(\frac{1}{K}\right)^{\theta} N_{t}^{\theta}
$$

Note that in case of a population without source restriction ( $K$ is huge) and with small $\theta$ we have $\left(\frac{1}{K}\right)^{\theta} \approx 1$. We can rewrite the above formula as:

$$
R_{t}=R_{\max }-R_{\max }\left(\frac{1}{K}\right)^{\theta} N_{t}^{\theta}=R_{\max }-a N_{t}^{\theta}
$$

with $a=R_{\max }\left(\frac{1}{K}\right)^{\theta}$.

\section{Fitting and validation procedure}

The root mean square error (RMSE) was defined as the root of the average sum of the squares of the differences between the observed $\left(R_{t}\right)$ and model predicted ( $R_{t, \text { pred }}$ ) values:

$$
\mathrm{RMSE}=\sqrt{\frac{1}{\mathrm{n}} \sum_{\mathrm{j}}\left(\mathrm{R}_{\mathrm{t}}-\mathrm{R}_{\mathrm{t}, \text { pred }}\right)^{2}}
$$

where $n$ denotes the number of years. RMSE was minimized while three parameters, namely the maximal growth rate $R_{\max }$, the carrying capacity $K$ and the power parameter $\theta$ were varied. For optimization we used Palisade's Risk Evolver that is based on 
innovative genetic algorithm (GA technology), a stochastic directed searching technique with several thousands of iteration. This method does not get stuck at local solutions, but instead looks at the entire range of possible solutions which enables us to find the global optimal solution instead of a local extreme value (Weise, 2009).

\section{Climatic Indicator Data Set}

From the meteorological daily data we calculated climatic indicators. We cut the 365 or 366 days of the years into decades (of ten days) and for a year $t$ we calculated

- the average of the daily mean temperatures of the $i^{\text {th }}$ decade (TM $\left.t-i\right)$

- the average of the daily minimum temperatures of the $i^{\text {th }}$ decade $\left(\mathrm{TN} t \_i\right)$

- the average of the daily maximum temperatures of the $i^{\text {th }}$ decade (TX $\left.t_{-} i\right)$

- the average of the daily precipitation of the $i^{\text {th }}$ decade $(\mathrm{P} t-i)$

- the minimum of the daily minimum temperatures of the $i^{\text {th }}$ decade $\left(\mathrm{TNN} t_{-} i\right)$

- the maximum of the daily maximum temperatures of the $i^{\text {th }}$ decade $\left(\mathrm{TXX} t_{-} i\right)$.

We also calculated the monthly climatic indicators as well:

- the average of the daily mean temperatures of the $j^{\text {th }}$ month $\left(\mathrm{TMm} t \_j\right)$

- the average of the daily minimum temperatures of the $j^{\text {th }}$ month $\left(\mathrm{TNm} t_{-} j\right)$

- the average of the daily maximum temperatures of the $j^{\text {th }}$ month $\left(\mathrm{TXm} t_{-} j\right)$

- the average of the daily precipitation of the $j^{\text {th }}$ month $(\operatorname{Pm} t j)$

- the minimum of the daily minimum temperatures of the $j^{\text {th }}$ month (TNNm $\left.t_{-} j\right)$

- the maximum of the daily maximum temperatures of the $j^{\text {th }}$ month $(\mathrm{TXXm} t j)$.

For $t=1973, \ldots, 1999$ the vector $\left(R_{t}\right)=\left(\ln \left(\frac{N_{t+1}}{N_{t}}\right)\right)$ was correlated with all the climatic indicator vectors $\left(I_{t}\right)$ and $\left(I_{t+1}\right)$ to find the connection between the population change from the year $t$ to the year $t+1$ denoted by $\left(R_{t}\right)=\left(\ln \left(\frac{N_{t+1}}{N_{t}}\right)\right)$ and the indicators of the year $t+1$ and the ones of the previous year $t$. The indicators with significantly high correlation values $R^{2}$ were selected. We have found some highly correlated indicators referring consecutive decades, thus we completed the indicator set with some extra indicators called summer (calculated from $20^{\text {th }}$ of July to $15^{\text {th }}$ of August) and fall (calculated from $15^{\text {th }}$ of October to $15^{\text {th }}$ of November) indicators as follows.

Between $20^{\text {th }}$ of July and $15^{\text {th }}$ of August:

- the average of the daily mean temperatures $\left(\mathrm{STM} t_{-} i\right)$

- the average of the daily minimum temperatures (STN $\left.t \_i\right)$

- the average of the daily maximum temperatures (STX $\left.t_{-} i\right)$

- the average of the daily precipitation $\left(\mathrm{SP} t \_i\right)$

- the minimum of the daily minimum temperatures of (STNN $t$ - $i)$

- the maximum of the daily maximum temperatures (STXX $\left.t_{-} i\right)$ and

between $15^{\text {th }}$ of October to $15^{\text {th }}$ of November:

- the average of the daily mean temperatures (FTM $\left.t \_i\right)$

- the average of the daily minimum temperatures $(\mathrm{FTN} t i$ ) 
- the average of the daily maximum temperatures (FTX $\left.t \_i\right)$

- the average of the daily precipitation $\left(\mathrm{FP} t \_i\right)$

- the minimum of the daily minimum temperatures (FTNN $\left.t \_i\right)$

- the maximum of the daily maximum temperatures (FTXX $\left.t \_i\right)$.

We created an indicator data base with the years in the first column, the $N_{t}$ values in the second one, and then we have 612 further columns:

$6 * 37 * 2$ columns for the decade indicators of 6 types, 37 decades, 2 years;

$6 * 12 * 2$ columns for the month indicators of 6 types, 12 months, 2 years;

$6 * 2 * 2$ columns for the extra indicators of 6 types, 2 seasons, 2 years.

\section{Model development}

Besides descibing the basic structure of the effect of endogenous and exogenous forces, with a more sophisticated model, we can express the impact of the climatic indicators as well. With this step we aim to refine the model for a better fitting solution. The form of the model is:

$$
R_{t}=R_{\max }-R_{\max }\left(\frac{1}{K}\right)^{\theta} N_{t}^{\theta}+\sum_{k} C_{k} I_{k}
$$

where $I_{k}$ are climatic indicators, $C_{k} \in \mathbf{R}$ are parameters to optimize.

First we took an only climatic indicator $I_{1}$, the one which has the highest correlation with the vector $\left(R_{t}\right)$. The root mean square error was minimized with innovative genetic algorithm while three plus one parameters, namely the maximal growth rate $R_{\max }$, the carrying capacity $K$ and the power parameter $\theta$ together with $C_{1}$ were varied in the parameter space. Then we took a second climatic indicator $I_{2}$ from the indicator data set, the one which has the (second) highest correlation with the vector $\left(R_{t}\right)$. Again, the root mean square error was minimized while one more parameter together with the formerly optimized four ones were varied. In each step we calculated the Akaike Information Criterion with a Bayesian bias-adjustment in case the number of parameters $k$ is large relative to the number of cases $n(n / k<40)$, which is the case we face (Turkheimer et al., 2003; Schwarz, 1978):

$$
A I C_{B}=n \ln \left(\frac{R M S E}{n}\right)+2 k+\frac{2 k(k+1)}{n-k-1}
$$

where $k$ denotes the number of parameters, $n$ is the number of fitted values (years).

We went on with more and more climatic indicators involved in the model step by step and calculated the Akaike Information Criterion. The model was selected as the best one which had its lowest $A I C_{B}$ value.

Moreover, in each step we calculated the explained variance ratio as well:

$$
R^{2}=\frac{\sum\left(R_{t, \text { pred }}-\overline{R_{t}}\right)^{2}}{\sum\left(R_{t}-\overline{R_{t}}\right)^{2}}
$$

where $\overline{R_{t}}$ denotes the average of the observed $R_{t}$ values. 


\section{Regional climate model prediction survey}

The calibrated best model was run with input coming from the regional climate model RegCM 3.1 for three time intervals: 1961-1990 as reference period, 2021-2050 and 2071-2100 for prediction. We calculated the $\left(R_{t}\right)$ predictions for these three time intervals. The results of the three time intervals were compared with one-way ANOVA after a logarithmic data transformation to make the data more suitable for ANOVA demands. We tested them with the so-called difference contrast expressed by the matrix $\left(\begin{array}{ccc}1 & -1 & 0 \\ 1 & 0 & -1 \\ 0 & 1 & -1\end{array}\right)$. Variance homogeneity was checked with Levene test. Normality of residuals was checked with Kolmogorov-Smirnov test.

The results of the three time intervals were than fitted by Beta distribution which has the general formula

$$
f(x)=\frac{(x-a)^{p-1}(b-x)^{q-1}}{B(p ; q)(b-a)^{p+q-1}}
$$

where the values of the variable are in between $a$ and $b ; p$ and $q$ are positive parameters of the distribution and the Beta function is as follows:

$$
B(p ; q)=\int_{0}^{1} t^{p-1}(1-t)^{q-1} d t
$$

The distribution fit was tested by Chi-square test. Finally the fitted distributions were compared.

The softwares PASW18 as well as @ Risk of Palisade were applied for data evaluations.

\section{Results}

We have selected 8 indicators which have significant Pearson correlation with $\left(R_{t}\right)$. The indicators are listed in Table 1.

Table 1. Selected indicators having significant Pearson correlation with $\left(R_{t}\right)$. Their $R$ values together with the significance levels are also shown. The descriptions of the indicators are listed under the table

\begin{tabular}{c|c|c}
\hline Indicator & Pearson Correlation R & Sig. (2-tailed) \\
TXXm $t$ APR & -0.546 & $0.003^{* *}$ \\
TXm $(\mathrm{t}+1)$ _FEB & 0.442 & $0.021^{*}$ \\
STM $(t+1) \_i$ & 0.427 & $0.026^{*}$ \\
TXXm $(t+1)$ MAY & -0.422 & $0.028^{*}$ \\
TNmt_MAR & 0.421 & $0.029^{*}$ \\
Pmt_SEP & -0.419 & $0.029^{*}$ \\
TNNm $(t+1) \_A P R$ & 0.392 & $0.043^{*}$ \\
TXXmt_JAN & -0.387 & $0.046^{*}$ \\
\hline
\end{tabular}

*significant with $\mathrm{p}<0.05 ; * *$ significant with $\mathrm{p}<0.01$ 
The indicators in Table 1 are as follows:

- TXXmt_APR: the maximum of the daily maximum temperatures in April in year $t$ which is for the temperature condition of the larvae of the parent generation;

- $\operatorname{TXm}(t+1) \_$FEB: the average of the daily maximum temperatures in February in year $t+1$ which is for the temperature condition of the new generation just before hatching;

- $\quad \operatorname{STM}(t+1) \_i$ the average of the daily mean temperatures between $20^{\text {th }}$ of July and $15^{\text {th }}$ of August in year $t+1$ which is for the temperature condition of the new generation in their pupal stage;

- $\operatorname{TXXm}(t+1) \_$MAY: the maximum of the daily maximum temperatures in May in year $t+1$ which is for the temperature condition of the new generation in their late larvae stage;

- TNm $t$ MAR the average of the daily minimum temperatures in March in year $t$ which is for the temperature condition of the parent generation in the hatching period;

- Pmt_SEP the average of the daily precipitation in September in year $t$ which is for the fall-time precipitation condition of the parent generation just before their swarming period;

- TNNm $(t+1) \_A P R:$ the minimum of the daily minimum temperatures in April in year $t+1$ for which is for the temperature condition of the new generation in their early larvae stage;

- TXXmt_JAN: the maximum of the daily maximum temperatures in January in year $t$ which is for the temperature condition of the parent generation just before hatching.

We extended the basic model step by step with the maximum of the daily maximum temperatures in April in year $t$ at first, then with the average of the daily maximum temperatures in February in year $t+1$, third time with the average of the daily mean temperatures between $20^{\text {th }}$ of July and $15^{\text {th }}$ of August in year $t+1$, fourth time with the maximum of the daily maximum temperatures in May in year $t+1$, fifth time with the average of the daily minimum temperatures in March in year $t$ and finally with the average of the daily precipitation in September in year $t$.

In Table 2 the results of the basic model $R_{t}=R_{\max }-R_{\max }\left(\frac{1}{K}\right)^{\theta} N_{t}^{\theta}$ as well as the ones of the extended model $R_{t}=R_{\max }-R_{\max }\left(\frac{1}{K}\right)^{\theta} N_{t}^{\theta}+\sum_{k} C_{k} I_{k}$ are presented. 


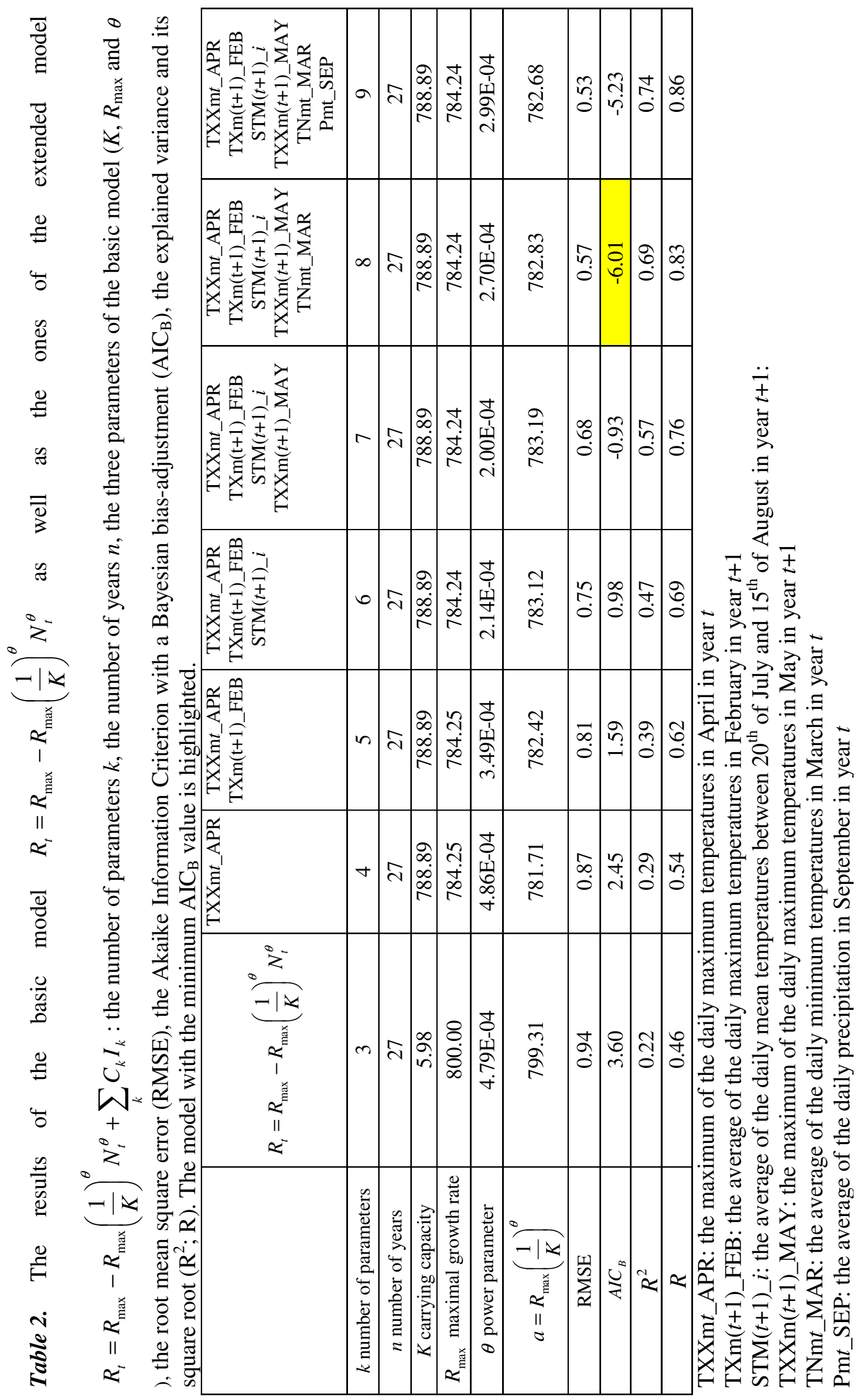

APPLIED ECOLOGY AND ENVIRONMENTAL RESEARCH 9(4): 433-447. 
According to the Akaike Information Criterion with a Bayesian bias-adjustment $\mathrm{AICB}=-6.01$ the best model was the one with the first five climatic indicators. The coefficients of the best model are listed in Table 3.

Table 3. The coefficients $C_{k}$ of the best model with the lowest $A I C_{B}$ value

\begin{tabular}{c|c|c|c|c}
\hline $\mathbf{T X X m} t_{-} \mathbf{A P R}$ & $\mathbf{T X m}(\mathbf{t + 1})_{-} \mathbf{F E B}$ & $\mathbf{S T M}(\boldsymbol{t + 1}) \_\boldsymbol{i}$ & $\mathbf{T X X m}(\boldsymbol{t + 1}) \_\mathbf{M A Y}$ & $\mathbf{T N m t} \_\mathbf{M A R}$ \\
\hline-0.111 & 0.065 & 0.172 & -0.112 & 0.186 \\
\hline
\end{tabular}

In Fig. 2 we can see the $R_{t}$ values calculated from the observed data as well as the estimated $R_{t}$ values of the basic ( $R^{2}=0.22, \mathrm{p}>0.1$ nonsignificant) and the extended model $\left(R^{2}=0.69, \mathrm{p}<0.001\right.$, highly significant $)$.

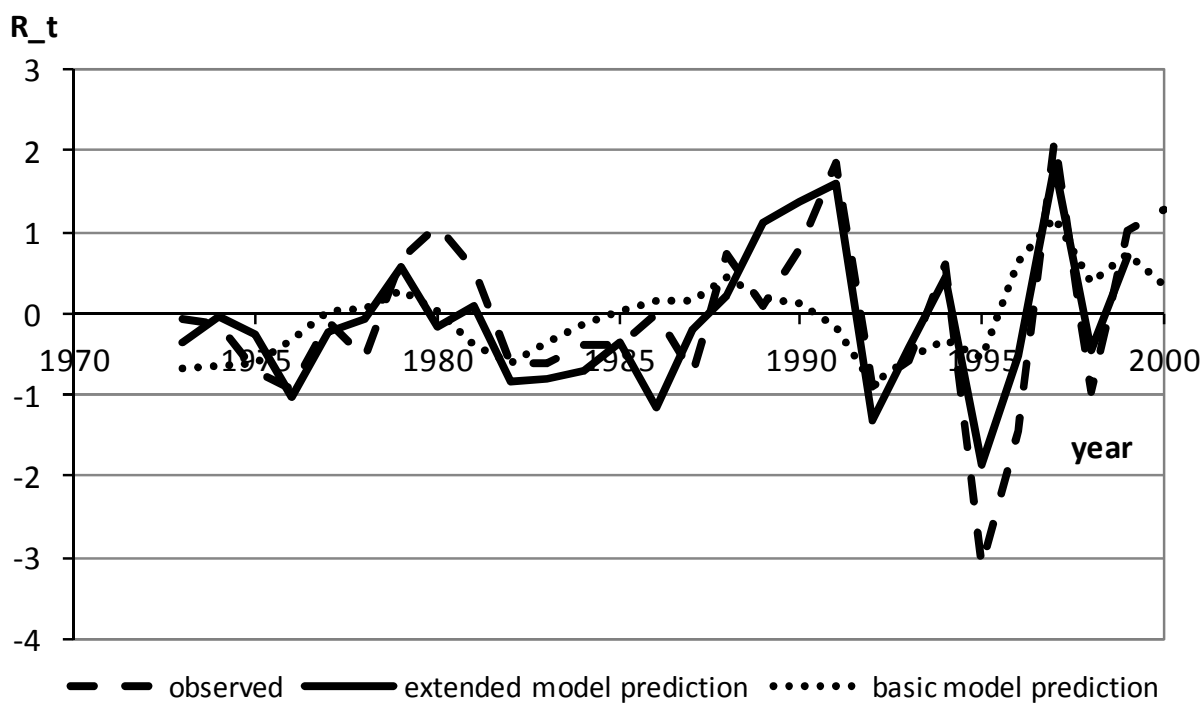

Figure 2. $R_{t}$ values calculated from the observed data as well as the estimated $R_{t}$ values of the basic $\left(R^{2}=0.22, p>0.1\right.$ nonsignificant $)$ and the extended model $\left(R^{2}=0.69, p<0.001\right.$, highly significant)

The extended model fits much better which clearly indicates the need of including climatic indicators in the population dynamical model derived by endogenous and exogenous factors, only.

In Fig. 3 we can observe that in two years the observed values were overestimated by the model. In the remaining years, however, the estimations generated quite low errors. 


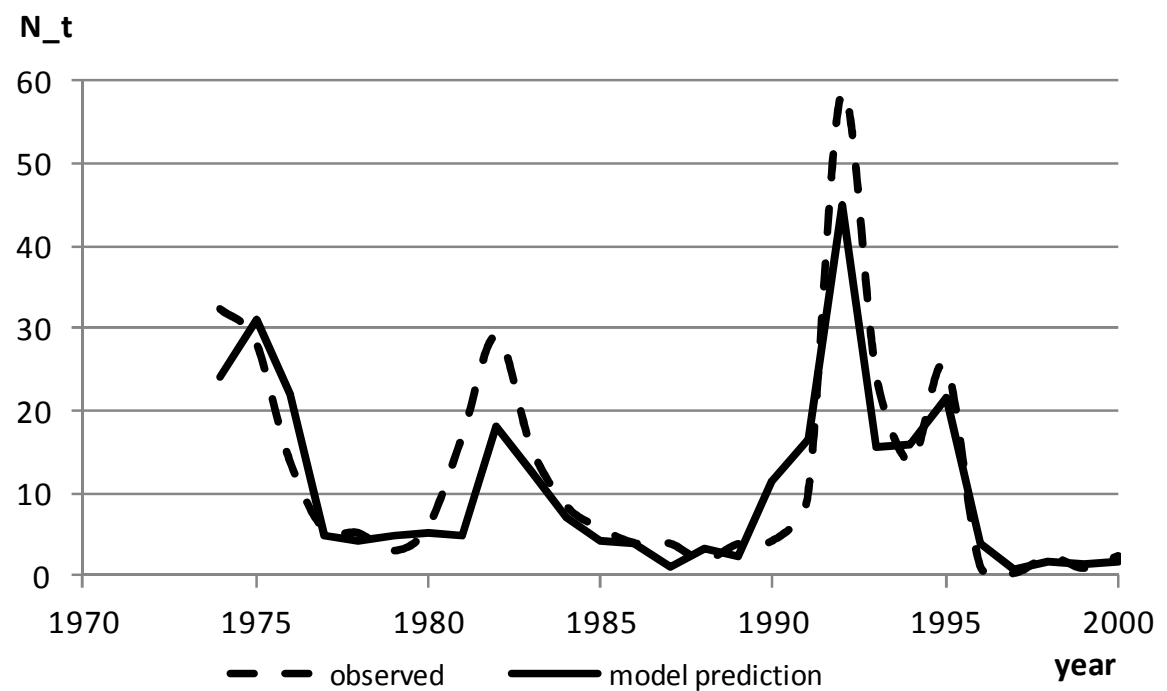

Figure 3. $N_{t}$ values calculated from the observed data as well as the estimated $N_{t}$ values of model extended by five climatic indicators

In Fig. 4 we can see the probability density of the model estimated $N_{t}$ values earned by running the extended model with RegCM3.1 daily climatic parameter outputs regarded the reference period 1961-1990 as well as the future predictions for the time intervals 2021-2050 and 2071-2100 (bars) together with their fitted Beta distributions.

We fitted the Beta distributions with fixed minimum and maximum parameters $(a=0$ and $b=55$ ) in order to ensure the comparability of the fitted functions. The $p$ and $q$ parameters and the result of fitting together with the descriptive statistics of the model outputs can be found in Table 4.

Table 4. The $p$ and $q$ parameters of the Beta distribution with $a=0$ and $b=55$ and the result of distribution fitting together with the descriptive statistics of the model outputs min, max, mean, standard deviation and coefficient of variation (CV) for three time intervals 1961-

1990 (as the reference), 2021-2050 and 2071-2100.

\begin{tabular}{c|c|c|c}
\hline & $\mathbf{1 9 6 1 - 1 9 9 0}$ & $\mathbf{2 0 2 1 - 2 0 5 0}$ & $\mathbf{2 0 7 1 - 2 1 0 0}$ \\
\hline$p$ & 0.98 & 0.93 & 0.60 \\
$q$ & 9.10 & 9.43 & 1.97 \\
Chi-square & 1.72 & 1.00 & 5.55 \\
Significance level & 0.89 & 0.96 & 0.35 \\
MIN & 0.22 & 0.16 & 0.20 \\
MAX & 18.93 & 21.89 & 54.02 \\
MEAN & 5.35 & 4.92 & 10.58 \\
St. dev. & 5.06 & 5.10 & 12.16 \\
CV & 0.95 & 1.04 & 1.15 \\
\hline
\end{tabular}

Comparing the model predictions of three time intervals 1961-1990 (as the reference), 2021-2050 and 2071-2100 by one-way ANOVA with difference contrast we can state that the intervals 1961-1990 and 2021-2050 do not differ from each other significantly $(p=0.735)$. The time scale 2071-2100, however is different from the first two intervals significantly $(\mathrm{p}<0.05)$. 

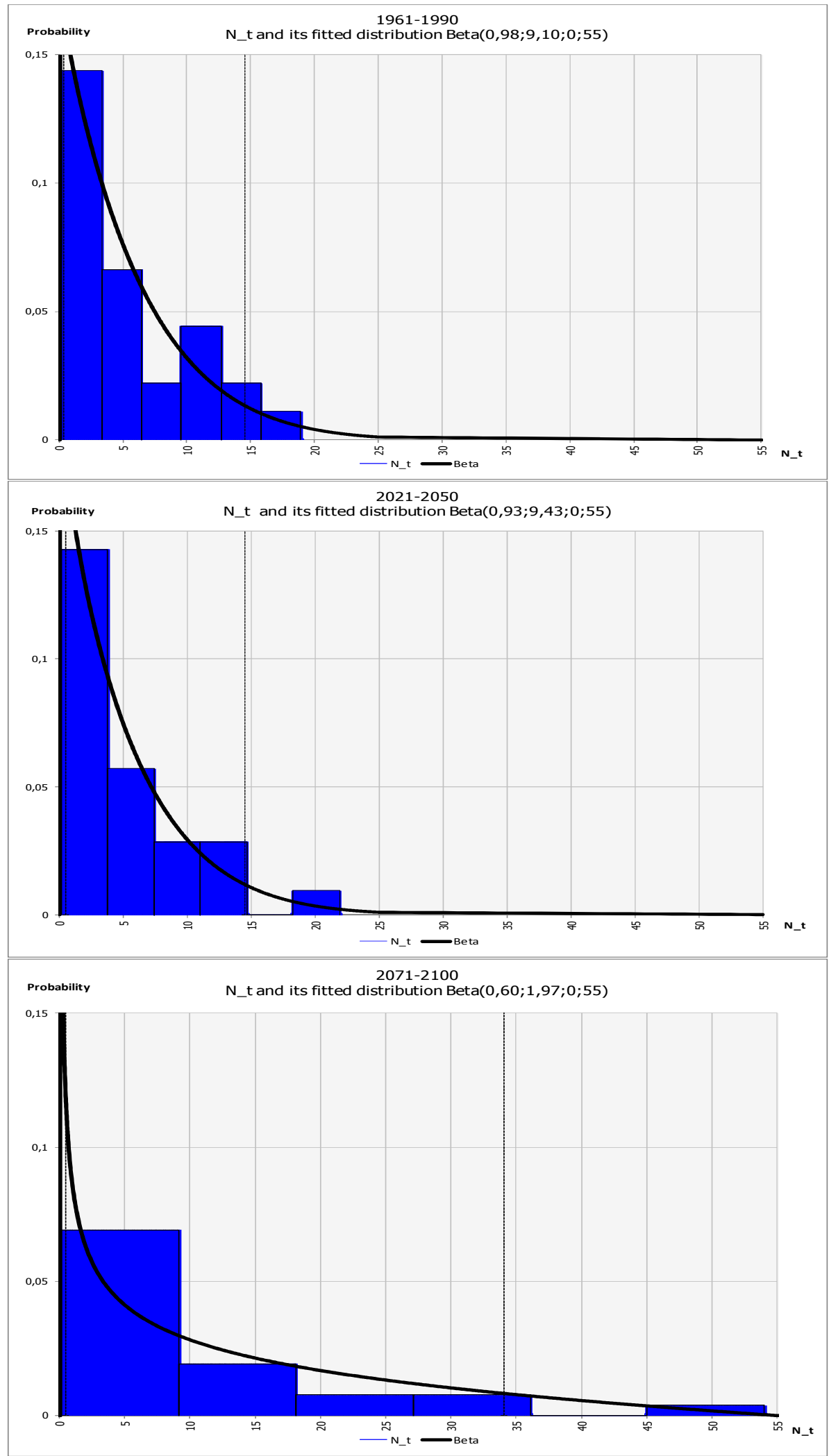

Figure 4. Probability density of the model estimated $N_{t}$ values earned by running the extended model with RegCM3.1 daily climatic parameter outputs regarded the reference period 19611990 as well as the future predictions for the time intervals 2021-2050 and 2071-2100 (bars). The lines are for the estimated Beta distributions 


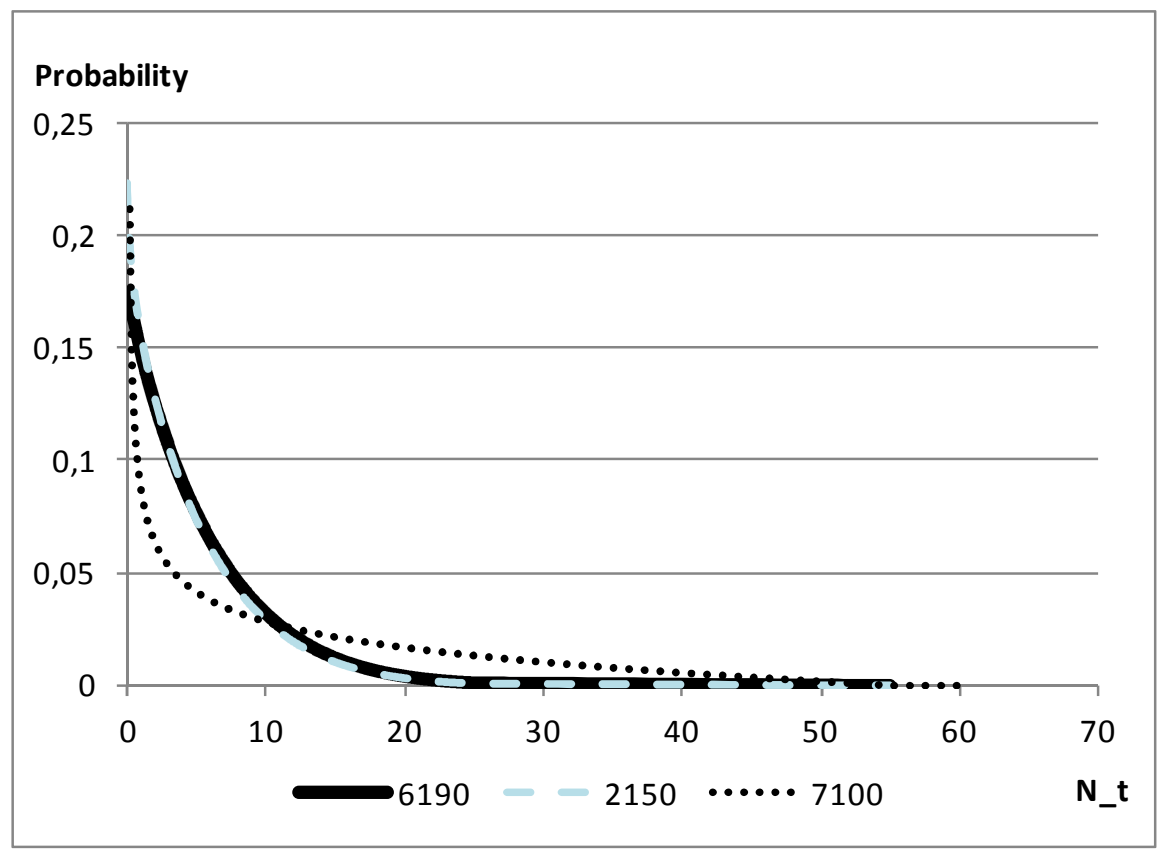

Figure 5. The Beta distributions fitted to the extended model predictions run by the RegCM3.1 outputs regarded the reference period 1961-1990 as well as the future time intervals 2021-2050 and 2071-2100.

In Fig. 4 we can see that the probability density functions of the time intervals 1961-1990 and 2021-2050 are very similar. Up to the end of the $21^{\text {st }}$ century, however, we can expect some years with a great number of swarming Operophtera brumata, L. which can be detected on the probability density function of time interval 2071-2100 shifted to the right. The mean, the maximum and the standard deviation of the results of this late time scale are also much higher than the ones of the earlier time intervals (Table 4). The same can be observed in Fig. 5 in which we can see the fitted Beta distributions. The probability of low number of swarming Operophtera brumata, L. is expected to decrease while the one of high-peaked smarming is increasing. It means that we can expect that with the better and better the climatic conditions of swarming of these insects can result a definitely increasing risk of damages as well.

We note that in order to avoid the aggregation of the errors of the two models (the extended population dynamical model and the RegCM3.1 regional climate model) we stressed the expected changes with their direction and magnitude. If we make conclusions based on the differences of the model outputs, than the effect of the systematic model errors are minimal.

Acknowledgements. We express our gratitude to professor Zoltán Mészáros D.Sc. for his useful advices. This work was supported by the research project of the National Development Agency TÁMOP 4.2.1/B09/1/KMR-2010-0005.

\section{REFERENCES}

[1] Bale, J., Masters, G., Hodkinson, I., Awmack, C., Bezemer, T., Brown, V., Butterfield, J., Buse, A., Coulson, J., Farrar, J., others (2002): Herbivory in global climate change research: direct effects of rising temperature on insect herbivores. - Glob. Chang. Biol. 8: $1-16$. 
[2] Bartholy, J., Pngrácz, R., Torma, Cs., Pieczka, I., Kardos, P., Hunyady, A. (2009): Analysis of regional climate change modelling experiments for the Carpathian basin. International Journal of Global Warming 1(1-2-3): 238-252.

[3] Berryman, A.A. (1999): Principles of population dynamics and their application. Stanley Thornes Publishers, Cheltenham (distributed by Taylor \& Francis, London)

[4] Cammell, M., Knight, J. (1992): Effects of climatic change on the population dynamics of crop pests. - Adv. Ecol. Res. 22: 117-162.

[5] Chinery, M.: Collins Guide to the Insects of Britain and Western Europe, 1986. (Reprinted 1991)

[6] Diós, N., Szenteleki, K., Ferenczy, A., Petrányi, G., Hufnagel, L. (2009): A Climate profile indicator based comparative analysis of climate change scenarios with regard to maize (Zea mays L.) cultures. - Applied Ecology and Environmental Research 7(3): 199214.

[7] Drégelyi-Kiss, Á., Drégelyi-Kiss, G., Hufnagel, L. (2008): Ecosystems As Climate Controllers - Biotic Feedbacks. - Applied Ecology And Environmental Research 6(2): 111-134.

[8] Drégelyi-Kiss, Á., Hufnagel, L. (2009): Simulations Of Theoretical Ecosystem Growth Model (Tegm) During arious Climate Conditions. - Applied Ecology And Environmental Research 7(1): 71-78.

[9] Estay, S.A., Lima, M., Labra, F.A. (2009): Predicting insect pest status under climate change scenarios: combining experimental data and population dynamics modelling. - J. Appl. Entomol. 133: 491-499.

[10] Gilpin, M.E., Ayala, F.J. (1973): Global models of growth and competition. - Proc. Natl. Acad. Sci. USA 70: 3590-3593.

[11] Gimesi, L., Hufnagel, L. (2010): The possibilities of biodiversity monitoring based on Hungarian light trap networks 1. - Applied Ecology and Environmental Research 8(3): 223-239.

[12] Giorgi, F., Marinucci, M.R., Bates, G.T. (1993): Development of a second generation regional climate model (RegCM2): Boundary layer and radiative transfer processes. Mon. Wea. Rev. 121: 2794-2813.

[13] Heuvelink, G.B.M., Webster, R. (2001): Modelling soil variation: past, present, and future. - Geoderma 100: 269-301.

[14] IPCC (2007): Fourth Assessment Report of the Intergovernmental Panel on Climate Change.(http://www.ipcc.ch/publications_and_data/publications_ipcc_fourth_assessment _report_synthesis_report.htm)

[15] Merrill, R., Gutie'rrez, D., Lewis, O., Gutie'rrez, J., Diez, S., Wilson, R., (2008): Combined effects of climate and biotic interactions on the elevational range of a phytophagous insect. - J. Anim. Ecol. 77: 145-155.

[16] Moon, Y., Kim, J. (2007): Efficient moving average transform-based subsequence matching algorithms in time-series databases. - Information Sciences 177: 5415-5431.

[17] Musolin, D. (2007): Insects in a warmer world: ecological, physiological and life-history responses of true bugs (Heteroptera) to climate change. - Glob. Chang. Biol. 13. 15651585 .

[18] Nelder, J.A. (1961): The fitting of a generalization of the logistic curve. - Biometrics 17: 89-110.

[19] Nowinszky, L., Puskás, J. (1998): Light trapping of winter moth (Operophthera brumata L.) at the time of weather fronts. - Berzsenyi Dániel College, Scientific Papers 2: 45-51.

[20] Olfert, O., Weiss, R. (2006): Impact of climate change on potential distributions and relative abundances of Oulema melanopus, Meligethes viridescens and Ceutorhynchus obstrictus in Canada. - Agric. Ecosyst. Environ. 113: 295-301.

[21] Parmesan, C. (2007): Influences of species, latitudes and methodologies on estimates of phenological response to global warming. - Glob. Chang. Biol. 13: 1860-1872. 
[22] Porter, J.H., Parry, M.L., Carter, T.R. (1991): The potential effects of climatic change on agricultural insect pest. - Agric. For. Meteorol. 57: 221-240.

[23] Richards, F.J. (1959): A flexible growth function for empirical use. - J. Exp Bot 10: 290300.

[24] Ricker, W.E. (1954): Stock and recruitment. - J. Fish. Res. Board Can. 115: 559-623.

[25] Robert, D, Childs, Amherst, M.A., Deborah, C.. Swanson, Hanson, M.A.: The Winter Moth (Operophtera brumata (L.)) - Umass Extension 2009: 1-5.

[26] Royama, T. (1992): Analytical Population Dynamics. - Chapman \& Hall, New York, 371 p.

[27] Schwarz, G. (1978): Estimating the dimension of a model. - Ann. Stat. 6: 461-464.

[28] Schwerdtfeger, F. (1969): Ökologie der Tiere-Demökologie. - Paul Parey. HamburgBerlin.

[29] Sipkay, Cs., Horváth, L., Nosek, J., Oertel, N., Vadadi-Fülöp, Cs., Farkas, E., DrégelyiKiss, Á., Hufnagel, L. (2008): Analysis Of Climate Change Scenarios Based On Modelling Of The Seasonal Dynamics Of A Danubian Copepod Species. - Applied Ecology And Environmental Research 6(4): 101-109.

[30] Sipkay, Cs., Kiss, K.T., Vadadi-Fülöp, Cs., Hufnagel, L. (2009): Trends In Research On The Possible Effects Of Climate Change Concerning Aquatic Ecosystems With Special Emphasis On The Modelling Approach. - Applied Ecology And Environmental Research 7(2): 171-198.

[31] Szontagh, P. (1980): Gradationverhältnisse der eichenschädlicher Geometriden Arten in Ungarn. - Prace Muzea V, Hradcy Kralove. 257-259.

[32] Torma, Cs., Bartholy, J., Pongrácz, R., Barcza, Z., Coppola, E., Giorgi, F. (2008): Adaptation and validation of the RegCM3 climate model for the Carpathian Basin. Időjárás 112(3-4): 233-247.

[33] Turkheimer, Hinz, Cunningham (2003): On the undecidability among kinetic models: from model selection to model averaging. - Journal of Cerebral Blood Flow \& Metabolism 23: 490-498.

[34] Verhulst, P.F. (1838): Notice sur la loi que la population suit dans son accrossement. Correspondance Math. Phys. 10: 113-121.

[35] Weise, T. (2009): Global Optimization Algorithms - Theory and Application http://www.it-weise.de/projects/book.pdf

[36] Woiwod, I. (1997): Detecting the effects of climate change on Lepidoptera. - J. Insect Conserv. 1: 149-158. 